\title{
A note on recent fixed point results involving $g$-quasicontractive type mappings in partially ordered metric spaces
}

Erdal Karapınar ${ }^{1,2^{*}}$ and Bessem Samet ${ }^{3}$

\section{"Correspondence:}

erdalkarapinar@yahoo.com;

ekarapinar@atilim.edu.tr

'Department of Mathematics,

Atilim University, Incek, Ankara 06836, Turkey

${ }^{2}$ Nonlinear Analysis and Applied Mathematics Research Group (NAAM), King Abdulaziz University, Jeddah, Saudi Arabia

Full list of author information is

available at the end of the article

\author{
Abstract \\ In this note, we establish the equivalence between recent fixed point theorems \\ involving quasicontractive type mappings in metric spaces endowed with a partial \\ order. \\ MSC: $47 \mathrm{H} 10$ \\ Keywords: g-quasicontraction; coincidence point; fixed point; partial order; metric \\ space
}

\section{Introduction}

Let $(X, d)$ be a metric space and let $f, g: X \rightarrow X$ be two self-maps on $X$. Let

$$
M(f, g, x, y):=\max \{d(g x, g y), d(g x, f x), d(g y, f y), d(g x, f y), d(g y, f x)\} \quad \text { for all } x, y \in X
$$

Suppose that $X$ is endowed with a partial order $\preceq$. We say that $f$ is an ordered $g$ quasicontraction (see $[1,2])$ if

$$
d(f x, f y) \leq \lambda M(f, g, x, y) \quad \text { for all } x, y \in X \text { such that } g y \preceq g x
$$

for some constant $\lambda \in(0,1)$. If $g=i d_{X}$ (the identity map on $\left.X\right)$, then $f$ is said to be an ordered quasicontraction.

In [1], the authors established the following result.

Theorem 1.1 Let $(X, d)$ be a metric space endowed with a certain partial order $\preceq$. Let $f, g: X \rightarrow X$ be two self-maps on $X$ satisfying the following conditions:

(i) $f X \subseteq g X$;

(ii) $g X$ is complete;

(iii) $f$ is $g$-nondecreasing, i.e., $g x \preceq g y \Longrightarrow f x \preceq f y$;

(iv) $f$ is an ordered $g$-quasicontraction;

(v) there exists $x_{0} \in X$ such that $g x_{0} \preceq f x_{0}$;

(vi) if $\left\{g x_{n}\right\}$ is a nondecreasing sequence (w.r.t. $\preceq$ ) that converges to some $g z \in g X$, then $g x_{n} \preceq g z$ for each $n \in \mathbb{N}$.

Then $f$ and $g$ have a coincidence point, i.e., there exists $z \in X$ such that $f z=g z$. 
Taking $g=i d_{X}$ in Theorem 1.1, we obtain immediately the following result.

Theorem 1.2 Let $(X, d)$ be a complete metric space endowed with a certain partial order $\preceq$. Let $f: X \rightarrow X$ be a self-map on $X$ satisfying the following conditions:

(iii) $f$ is nondecreasing, i.e., $x \preceq y \Longrightarrow f x \preceq f y$;

(iv) $f$ is an ordered quasicontraction;

(v) there exists $x_{0} \in X$ such that $x_{0} \preceq f x_{0}$;

(vi) if $\left\{x_{n}\right\}$ is a nondecreasing sequence (w.r.t. $\preceq$ ) that converges to some $z \in X$, then $x_{n} \preceq z$ for each $n \in \mathbb{N}$.

Then $f$ has a fixed point.

Let us denote by $\Psi$ the set of functions $\psi:[0, \infty) \rightarrow[0, \infty)$ satisfying the following conditions:

$\left(\Psi_{1}\right) \psi$ is nondecreasing;

$\left(\Psi_{2}\right) \quad \psi$ is subadditive, i.e., $\psi(s+t) \leq \psi(s)+\psi(t)$, for every $s, t \geq 0$;

$\left(\Psi_{3}\right) \psi$ is continuous;

$\left(\Psi_{4}\right) \psi(t)=0 \Longleftrightarrow t=0$.

In [3], the authors established the following result.

Theorem 1.3 Let $(X, d)$ be a metric space endowed with a certain partial order $\preceq$. Let $f, g: X \rightarrow X$ be two self-maps on $X$ satisfying the following conditions:

(i) $f X \subseteq g X$;

(ii) $g X$ is complete;

(iii) $f$ is $g$-nondecreasing;

(iv) there exists $\psi \in \Psi$ such that

$$
\begin{gathered}
\psi(d(f x, f y)) \leq \lambda \max \{\psi(d(g x, g y)), \psi(d(g x, f x)), \psi(d(g y, f y)), \\
\psi(d(g x, f y)), \psi(d(g y, f x))\}
\end{gathered}
$$

for all $x, y \in X$ such that $g y \preceq g x$;

(v) there exists $x_{0} \in X$ such that $g x_{0} \preceq f x_{0}$;

(vi) if $\left\{g x_{n}\right\}$ is a nondecreasing sequence that converges to some $g z \in g X$, then $g x_{n} \preceq g z$ for each $n \in \mathbb{N}$.

Then $f$ and $g$ have a coincidence point.

The aim of this note is to prove that Theorems 1.1,1.2 and 1.3 are equivalent.

\section{Main result}

Our main result in this note is the following.

Theorem 2.1 We have the following equivalence:

$$
\text { Theorem } 1.2 \Longleftrightarrow \text { Theorem } 1.1 \Longleftrightarrow \text { Theorem 1.3. }
$$

Proof We consider three steps in the proof. 
$\diamond$ Step 1. Theorem $1.2 \Longrightarrow$ Theorem 1.1.

Suppose that all the assumptions of Theorem 1.1 are satisfied. Recall that if $S: X \rightarrow X$ is a given map, then there exists a subset $E$ of $X$ such that $S E=S X$ and $S: E \rightarrow X$ is oneto-one. For the proof of this result, we refer to [4]. Due to this remark, there exists $E \subseteq X$ such that $g E=g X$ and $g: E \rightarrow X$ is one-to-one. Let us define the map $T: g E \rightarrow g E$ by

$$
T(g x)=f x, \quad x \in E .
$$

Notice that the mapping $T$ is well defined since $g$ is one-to-one on $E$. From condition (ii) of Theorem 1.1, the metric space $(g E, d)$ is complete. From condition (iii) of Theorem 1.1, the mapping $T$ is nondecreasing. Observe also that $T$ is an ordered quasicontraction. Indeed, if $u, v \in g E$ such that $v \preceq u$, from condition (iv) of Theorem 1.1 and the definition of $g E$, there exist $x, y \in E$ with $v=g y \preceq g x=u$ such that

$$
\begin{aligned}
d(T u, T v) & =d(f x, f y) \\
& \leq \lambda M(f, g, x, y) \\
& =\lambda \max \{d(g x, g y), d(g x, f x), d(g y, f y), d(g x, f y), d(g y, f x)\} \\
& =\lambda \max \{d(u, v), d(u, T u), d(v, T v), d(u, T v), d(v, T u)\} .
\end{aligned}
$$

From condition (v) of Theorem 1.1, there exists $x_{0} \in X$ such that $g x_{0} \preceq f x_{0}$. Let $u_{0}=g x_{0} \in$ $g E$, we have $u_{0} \preceq T u_{0}$. Finally, from condition (iv) of Theorem 1.1, if $\left\{u_{n}\right\} \subset g E$ is a nondecreasing sequence that converges to some $u \in g E$, then $u_{n} \preceq u$ for each $n \in \mathbb{N}$. Thus we proved that $T$ satisfies all the conditions of Theorem 1.2. Then we deduce that $T$ has a fixed point $u^{*} \in g E$. This means that there exists some $x^{*} \in X$ such that $f x^{*}=T\left(g x^{*}\right)=g x^{*}$, that is, $x^{*} \in X$ is a coincidence point of $f$ and $g$.

$\diamond$ Step 2. Theorem $1.1 \Longrightarrow$ Theorem 1.3.

Suppose that all the assumptions of Theorem 1.3 are satisfied. Define the function $d_{\psi}$ : $X \times X \rightarrow[0, \infty)$ by

$$
d_{\psi}(x, y):=\psi(d(x, y)) \text { for all } x, y \in X \text {. }
$$

In [5], we proved that $d_{\psi}$ is a metric on $X$. Moreover, $(X, d)$ is complete if and only if $\left(X, d_{\psi}\right)$ is complete. Then from condition (iv) of Theorem 1.3, we deduce that $f$ is an ordered $g$ quasicontraction with respect to the new metric $d_{\psi}$. More precisely, we have

$$
d_{\psi}(f x, f y) \leq \lambda \max \left\{d_{\psi}(g x, g y), d_{\psi}(g x, f x), d_{\psi}(g y, f y), d_{\psi}(g x, f y), d_{\psi}(g y, f x)\right\}
$$

for all $x, y \in X$ such that $g y \preceq g x$. Now, applying Theorem 1.1 with the metric space $\left(X, d_{\psi}\right)$, we obtain the result of Theorem 1.3.

$\diamond$ Step 3. Theorem $1.3 \Longrightarrow$ Theorem 1.2.

Taking $g=i d_{X}$ and $\psi(t)=t$ in Theorem 1.3, we obtain immediately the result of Theorem 1.2. 


\section{Competing interests}

The authors declare that they have no competing interests.

\section{Authors' contributions}

All authors contributed equally and significantly in writing this article. All authors read and approved the final manuscript.

\section{Author details}

${ }^{1}$ Department of Mathematics, Atilim University, Incek, Ankara 06836, Turkey. ${ }^{2}$ Nonlinear Analysis and Applied Mathematics Research Group (NAAM), King Abdulaziz University, Jeddah, Saudi Arabia. ${ }^{3}$ Department of Mathematics, King Saud University, Riyadh, Saudi Arabia.

\section{Acknowledgements}

The authors thank the Visiting Professor Programming at King Saud University for funding this work. The authors thank the anonymous referees for their remarkable comments, suggestions and ideas that helped to improve this paper.

Received: 5 March 2014 Accepted: 13 May 2014 Published: 23 May 2014

\section{References}

1. Golubović, Z, Kadelburg, Z, Radenović, S: Common fixed points of ordered g-quasicontractions and weak contractions in ordered metric spaces. Fixed Point Theory Appl. 2012, 20 (2012)

2. Liu, X: Common fixed points of ordered G-contractions in partially ordered metric spaces. Fixed Point Theory Appl. 2014, $28(2014)$

3. Liu, X, Ješić, S: Common fixed points of a generalized ordered $g$-quasicontraction in partially ordered metric spaces. Fixed Point Theory Appl. 2013, 53 (2013)

4. Haghi, RH, Rezapour, S, Shahzad, N: Some fixed point generalizations are not real generalizations. Nonlinear Anal. 74 1799-1803 (2011)

5. Karapınar, E, Samet, B: A note on $\psi$-Geraghty type contractions. Fixed Point Theory Appl. 2014, 26 (2014)

10.1186/1687-1812-2014-126

Cite this article as: Karapınar and Samet: A note on recent fixed point results involving $g$-quasicontractive type mappings in partially ordered metric spaces. Fixed Point Theory and Applications 2014, 2014:126

\section{Submit your manuscript to a SpringerOpen ${ }^{\circ}$ journal and benefit from:}

- Convenient online submission

- Rigorous peer review

Immediate publication on acceptance

Open access: articles freely available online

- High visibility within the field

- Retaining the copyright to your article 